\title{
Yarrowia lipolytica application as a prospective approach for biosynthesis of pyruvic acid from glycerol
}

\author{
Krzysztof Cybulski ${ }^{1}$. Ludwika Tomaszewska-Hetman ${ }^{1}$ (D) - Waldemar Rymowicz ${ }^{1}$ Magdalena Rakicka ${ }^{1}$. \\ Anita Rywińska ${ }^{1}$
}

Received: 21 February 2018 / Accepted: 22 May 2018 / Published online: 29 June 2018

(c) The Author(s) 2018

\begin{abstract}
With the problems related to chemical methods of pyruvic acid (PA) synthesis, a fast-growing interest has been observed in research aiming at reducing the production cost of PA by applying biotechnological methods. This study aimed to investigate the potential applicability of Yarrowia lipolytica Wratislavia 1.31 yeast strain for valorisation of pure and crude glycerol through the production of industrially desired PA. Conditions required for the effective PA biosynthesis, i.e., $\mathrm{pH}$ value, thiamine concentration, agitation, and substrate concentration, were examined in batch and fed-batch cultivation modes. The efficient production of PA occurred under the limitation of thiamine $\left(1 \mu \mathrm{g} \mathrm{L}^{-1}\right)$ and was stimulated by moderate $\mathrm{pH}(4.5)$ and agitation $\left(800 \mathrm{rev}^{-1}\right.$ ) of the culture. Under optimal conditions, Y. lipolytica Wratislavia 1.31 was able to produce $85.2 \mathrm{~g}$ $\mathrm{L}^{-1}$ of PA with volumetric productivity of $0.90 \mathrm{~g} \mathrm{~L}^{-1} \mathrm{~h}^{-1}$. The yield of PA biosynthesis reached a high level of $1.03 \mathrm{~g} \mathrm{~g}^{-1}$. Obtained results confirmed the aptitude of $Y$. lipolytica yeast to produce high amounts of PA from simple glycerol-containing media. Presented process was very promising and might be considered as an attractive alternative for currently used chemical methods of PA synthesis.
\end{abstract}

Keywords Pyruvic acid production $\cdot \alpha$-ketoglutaric acid $\cdot$ Glycerol $\cdot$ Yarrowia lipolytica $\cdot$ Culture conditions

\begin{tabular}{|c|c|}
\hline \multicolumn{2}{|c|}{ Abbreviations } \\
\hline$X$ & Biomass $\left(\mathrm{g} \mathrm{L}^{-1}\right)$ \\
\hline PA & Pyruvic acid $\left(\mathrm{g} \mathrm{L}^{-1}\right)$ \\
\hline KGA & $\alpha$-ketoglutaric acid $\left(\mathrm{g} \mathrm{L}^{-1}\right)$ \\
\hline Y & Pyruvic acid production yield $\left(\mathrm{g} \mathrm{g}^{-1}\right)$ \\
\hline$Q$ & Volumetric productivity of pyruvate $\left(\mathrm{g} \mathrm{L}^{-1} \mathrm{~h}^{-1}\right)$ \\
\hline$q$ & Specific production rate of pyruvic acid $\left(\mathrm{g} \mathrm{g}^{-1} \mathrm{~h}^{-1}\right)$ \\
\hline$\eta_{\mathrm{PA}}$ & Yield coefficient of PA production \\
\hline
\end{tabular}

\section{Introduction}

Pyruvic acid (PA), a final compound of glycolysis, is an intermediate of a key role in metabolism as it is involved in pathways leading to formation of proteins, carbohydrates, and lipids. Its distinctive structure, comprising reactive carboxyl and ketone groups, offers the opportunity of

Ludwika Tomaszewska-Hetman

ludwika.tomaszewska-hetman@upwr.edu.pl

1 Department of Biotechnology and Food Microbiology, Wrocław University of Environmental and Life Sciences, Chełmońskiego Str. 37, 51-630 Wrocław, Poland application as a starting material for chemical synthesis of valuable products including pharmaceuticals such as L-tryptophan, L-tyrosine, 3-4-dihydroxyphenylalanine (DOPA), $\mathrm{N}$-acetyl- $D$-neuraminic acid (sialic acid), or R-phenylacetylcarbinol (PAC). Moreover, growing interest in PA has been observed for use in food, cosmetics, and agrochemical industry (Maleki and Eiteman 2017; Li et al. 2001; Xu et al. 2008). However, the current expensive chemical methods of PA synthesis determine the high price of pyruvate which is a major reason limiting its use on a large scale. Chemical PA synthesis raises objections also due to the fact that it causes environmental pollution.

With the well-known problems related to chemical methods of PA synthesis, a great potential has appeared for the biotechnological methods. Hence, a fast-growing interest in research aiming at reducing the production cost of PA by applying methods of direct fermentation (Izumi et al. 1982; Kamzolova and Morgunow 2016; Wang et al. 2016; Yang et al. 2014; Yokota et al. 1994), resting cell fermentation (Ogawa et al. 2001; Moriguchi et al. 1984), and enzymatic or whole-cell bioconversion (Eisenberg et al. 1997; Ma et al. 2004; Hao et al. 2007). Direct fermentation seems to be the most advantageous method as it permits to obtain a product 
of high purity and is cost-effective thanks to the possibility of sustainable substrate application (Zelić et al. 2004). The possible impediment of this method is its relatively low productivity due to the difficulty of acquiring a strain capable of extracellular production of PA in satisfactory amounts (Song et al. 2016; Li et al. 2001). Even though PA is formed in central metabolic pathways of microorganisms, small amounts have been reported to be found (Maleki and Eiteman 2017). Nevertheless, effective production of PA requires minimized transformation of this metabolite in further steps of metabolism. It was demonstrated that it can be achieved by optimizing medium composition in processes employing auxotrophs Torulopsis glabrata and Escherichia coli, two microorganisms primarily used for the production of pyruvate ( $\mathrm{Li}$ et al. 2002; Liu et al. 2006). In the fermentation processes of producing PA, glucose is mainly used as the substrate, and in years of research, much effort has been put to accelerate glycolysis to enhance glucose metabolism towards PA ( $\mathrm{Li}$ et al. 2001, 2002; Song et al. 2016). Morgunov et al. (2004) reported that a yeast strain of $Y$. lipolytica was able to produce PA in glycerol-containing medium. However, up-todate scientific data lack other information about potential application of these yeast in the production of PA.

The aim of the presented study was to investigate the possibility of PA production from pure and crude glycerol by $Y$. lipolytica Wratislavia 1.31 as well as to determine conditions required for the effective process of PA biosynthesis utilizing the examined yeast strain.

\section{Experimental}

Wratislavia 1.31 strain of Yarrowia lipolytica yeast (Rywińska et al. 2012) belonging to the Collection of the Department of Biotechnology and Food Microbiology (University of Environmental and Life Sciences, Wrocław, Poland) was used in the experiments presented in this report.

In the presented study, pure glycerol (purity of $98 \% \mathrm{wt}$ $\mathrm{wt}^{-1 ;}$ POCH, Gliwice, Poland) or crude glycerol (83\% wt $\mathrm{wt}^{-1}$ of glycerol and $7.3 \% \mathrm{wt} \mathrm{wt}^{-1}$ of $\mathrm{NaCl}$; Wratislavia-BIO, Wrocław, Poland) was applied as carbon and energy sources.

Medium used for preparation of inoculation culture contained the following constituents $\left(\mathrm{g} \mathrm{L}^{-1}\right)$ dissolved in distilled water: pure glycerol, 50.0; YNB (Yeast Nitrogen Base medium, Sigma-Aldrich), 0.067.

To examine the impact of $\mathrm{pH}$ value on PA production, the studied yeast was grown in a bioreactor medium containing $\left(\mathrm{g} \mathrm{L}^{-1}\right)$ : pure glycerol, 100.0; $\left(\mathrm{NH}_{4}\right)_{2} \mathrm{SO}_{4}, 10.0$; $\mathrm{MgSO}_{4} \cdot 7 \mathrm{H}_{2} \mathrm{O}, 1.4 ; \mathrm{KH}_{2} \mathrm{PO}_{4}, 2.0 ; \mathrm{Ca}\left(\mathrm{NO}_{3}\right)_{2}, 0.8 ; \mathrm{NaCl}, 0.5$ dissolved in tap water and in $\mathrm{pH}$ set in the range of 3.0-5.5 (Table 1). The same medium was also applied in the experiments focused on determining thiamine concentration and stirrer speed. However, in those cases, the medium was additionally supplemented with thiamine in the concentration of 0-3.5 $\mu \mathrm{g} \mathrm{L}^{-1}$ (Table 2) and with $1 \mu \mathrm{g} \mathrm{L}^{-1}$ (Table 3), respectively. When substrate concentration was tested in batch culture, bioreactor medium supplemented with $1 \mu \mathrm{g} \mathrm{L}^{-1}$ of thiamine and $150 \mathrm{~g} \mathrm{~L}^{-1}$ of glycerol was used.
Table 1 Impact of medium $\mathrm{pH}$ value on the biosynthesis of pyruvic acid from glycerol by Wratislavia 1.31 strain of Y. lipolytica

\begin{tabular}{lrllllll}
\hline $\mathrm{pH}$ & $X\left(\mathrm{~g} \mathrm{~L}^{-1}\right)$ & $\mathrm{PA}\left(\mathrm{g} \mathrm{L}^{-1}\right)$ & $\mathrm{KGA}\left(\mathrm{g} \mathrm{L}^{-1}\right)$ & $Y\left(\mathrm{~g} \mathrm{~g}^{-1}\right)$ & $Q\left(\mathrm{~g} \mathrm{~L}^{-1} \mathrm{~h}^{-1}\right)$ & $q\left(\mathrm{~g} \mathrm{~g}^{-1} \mathrm{~h}^{-1}\right)$ & PA/total acids \\
\hline 3.0 & $7.4 \pm 0.4$ & $39.0 \pm 4.4$. & $15.4 \pm 1.7$ & 0.38 & 0.38 & 0.05 & 0.72 \\
3.5 & $8.5 \pm 0.4$ & $44.4 \pm 4.1$ & $14.7 \pm 2.2$ & 0.43 & 0.57 & 0.07 & 0.75 \\
4.0 & $9.3 \pm 0.3$ & $50.5 \pm 3.5$ & $12.2 \pm 1.8$ & 0.50 & 0.67 & 0.07 & 0.81 \\
4.5 & $11.6 \pm 0.5$ & $55.0 \pm 5.6$ & $11.9 \pm 1.5$ & 0.54 & 0.75 & 0.07 & 0.82 \\
5.0 & $12.1 \pm 0.4$ & $53.5 \pm 4.9$ & $10.4 \pm 2.5$ & 0.47 & 0.73 & 0.06 & 0.84 \\
5.5 & $11.8 \pm 0.6$ & $38.0 \pm 3.8$ & $11.7 \pm 1.7$ & 0.37 & 0.51 & 0.06 & 0.76 \\
\hline
\end{tabular}

Culture conditions: $100 \mathrm{~g} \mathrm{~L}^{-1}$ of glycerol, no thiamine supplementation, and agitation rate of $800 \mathrm{rev} \mathrm{min}^{-1}$
Table 2 Pyruvic production parameters in dependence on different thiamine content in glycerol media during biosynthesis by $Y$. lipolytica Wratislavia 1.31

\begin{tabular}{lccccccc}
\hline $\begin{array}{l}\text { Thiamine } \\
\left(\mu \mathrm{g} \mathrm{L}^{-1}\right)\end{array}$ & $X\left(\mathrm{~g} \mathrm{~L}^{-1}\right)$ & $\mathrm{PA}\left(\mathrm{g} \mathrm{L}^{-1}\right)$ & $\mathrm{KGA}\left(\mathrm{g} \mathrm{L}^{-1}\right)$ & $Y\left(\mathrm{~g} \mathrm{~g}^{-1}\right)$ & $Q\left(\mathrm{~g} \mathrm{~L}^{-1} \mathrm{~h}^{-1}\right)$ & $q\left(\mathrm{~g} \mathrm{~g}^{-1} \mathrm{~h}^{-1}\right)$ & PA/total acids \\
\hline 0 & $11.6 \pm 0.6$ & $55.0 \pm 2.9$ & $11.9 \pm 2.2$ & 0.54 & 0.75 & 0.047 & 0.82 \\
0.5 & $12.2 \pm 1.6$ & $55.8 \pm 3.6$ & $10.2 \pm 3.0$ & 0.56 & 0.76 & 0.046 & 0.85 \\
1 & $12.9 \pm 2.2$ & $57.8 \pm 4.1$ & $7.2 \pm 1.5$ & 0.56 & 0.83 & 0.043 & 0.89 \\
1.5 & $13.6 \pm 2.2$ & $50.1 \pm 3.3$ & $8.3 \pm 1.7$ & 0.51 & 0.73 & 0.038 & 0.86 \\
2.5 & $14.0 \pm 2.7$ & $47.0 \pm 4.2$ & $7.5 \pm 3.1$ & 0.47 & 0.63 & 0.034 & 0.86 \\
3.5 & $14.4 \pm 1.8$ & $45.0 \pm 3.9$ & $8.7 \pm 1.5$ & 0.46 & 0.63 & 0.032 & 0.84 \\
\hline
\end{tabular}

Culture conditions: $100 \mathrm{~g} \mathrm{~L}^{-1}$ of glycerol, $\mathrm{pH} 4.5$, agitation rate of $800 \mathrm{rev} \mathrm{min}^{-1}$ 
Table 3 Biosynthesis of pyruvic acid from glycerol by $Y$. lipolytica Wratislavia 1.31 at various agitation rate

\begin{tabular}{|c|c|c|c|c|c|c|c|}
\hline $\begin{array}{l}\text { Agitation rate } \\
\left(\text { rev } \min ^{-1}\right)\end{array}$ & $X\left(\mathrm{~g} \mathrm{~L}^{-1}\right)$ & $\mathrm{PA}\left(\mathrm{g} \mathrm{L}^{-1}\right)$ & $\mathrm{KGA}\left(\mathrm{g} \mathrm{L}^{1}\right)$ & $Y\left(\mathrm{~g} \mathrm{~g}^{-1}\right)$ & $Q\left(\mathrm{~g} \mathrm{~L}^{-1} \mathrm{~h}^{-1}\right)$ & $q\left(\mathrm{~g} \mathrm{~g}^{-1} \mathrm{~h}^{-1}\right)$ & PA/total acids \\
\hline 600 & $12.1 \pm 1.9$ & $49.5 \pm 4.2$ & $9.8 \pm 2.0$ & 0.46 & 0.72 & 0.06 & 0.83 \\
\hline 800 & $12.9 \pm 1.6$ & $57.8 \pm 2.6$ & $7.2 \pm 0.4$ & 0.56 & 0.83 & 0.06 & 0.89 \\
\hline 1000 & $11.3 \pm 1.5$ & $53.0 \pm 5.2$ & $9.2 \pm 1.3$ & 0.48 & 0.74 & 0.07 & 0.85 \\
\hline $1000 / 800$ & $9.2 \pm 2.4$ & $55.1 \pm 2.5$ & $5.6 \pm 2.3$ & 0.54 & 0.82 & 0.08 & 0.91 \\
\hline
\end{tabular}

Culture conditions: $100 \mathrm{~g} \mathrm{~L}^{-1}$ of glycerol, thiamine concentration of $1 \mu \mathrm{g} \mathrm{L}^{-1}$, and $\mathrm{pH} 4.5$

In fed-batch mode, pure or crude glycerol $\left(150 \mathrm{~g} \mathrm{~L}^{-1}\right)$ was applied as the substrate. The initial medium was prepared with the use of $\left(\mathrm{g} \mathrm{L}^{-1}\right)$ : glycerol, $60 ;\left(\mathrm{NH}_{4}\right)_{2} \mathrm{SO}_{4}, 10.0$; $\mathrm{MgSO}_{4} \cdot 7 \mathrm{H}_{2} \mathrm{O}, 1.4 ; \mathrm{KH}_{2} \mathrm{PO}_{4}, 2.0 ; \mathrm{Ca}\left(\mathrm{NO}_{3}\right)_{2}, 0.8 ; \mathrm{NaCl}, 0.5$; thiamine, $1 \mu \mathrm{g}$, dissolved in tap water. During the cultivation process, the remaining quantity of the substrate was added to the culture broth in two portions of about $45 \mathrm{~g} \mathrm{~L}^{-1}$ each (Fig. 2).

Inoculation culture was performed in $300 \mathrm{~mL}$ flasks containing $100 \mathrm{~mL}$ of appropriate medium and put on a shaker (Certomat IS, Sartorius Stedim Biotech GmbH, Germany) at $140 \mathrm{rev} \mathrm{min}{ }^{-1}$ and a temperature of $30^{\circ} \mathrm{C}$ for $72 \mathrm{~h}$. Next, $200 \mathrm{~mL}$ of the culture was used for bioreactor medium inoculation.

Bioreactor cultures were carried out in Biostat B+bioreactor (Sartorius, Germany) in the working volume of $2 \mathrm{~L}$. If not otherwise indicated, the parameters were set at $30^{\circ} \mathrm{C}$, $0.6 \mathrm{vvm}, 800 \mathrm{rev} \mathrm{min}^{-1}$, and $\mathrm{pH}$ of 4.5 was maintained automatically by the addition of $40 \% \mathrm{NaOH}$ solution. Part of the experiments were meant to examine the impact of stirrer speed of $600-1000 \mathrm{rev}^{-1} \mathrm{~min}^{-1}$ (Table 3) and $\mathrm{pH}$ value of 3.0-5.5 (Table 1).

All the bioreactor cultures were performed in three replicates and standard deviations were calculated. In the samples, the analysis of the biomass, concentrations of glycerol, pyruvic acid (PA), and $\alpha$-ketoglutaric acid (KGA) were determined as described by Cybulski et al. 2018.

\section{Results and discussion}

\section{Determination of optimal pH for PA biosynthesis by Y. lipolytica}

Studies up-to-date report that high extracellular concentration of PA (exceeding $45 \mathrm{~g} \mathrm{~L}^{-1}$ ) might significantly inhibit further formation of this acid and lead to a decline in parameters of the biosynthesis process. Moreover, in case of PA, the inhibitory effect of the end-product might be enhanced at low $\mathrm{pH}$ at which time a toxic effect of undissociated form of the acid occurs (Liu et al. 2006). Therefore, maintaining an optimal level of $\mathrm{pH}$ during the process of microbial PA production seems to be of great importance. To determine the appropriate $\mathrm{pH}$ value for effective production of $\mathrm{PA}, Y$. lipolytica Wratislavia 1.31 was cultivated in bioreactor cultures in the media with $\mathrm{pH}$ value ranging from 3.0 to 5.5. The increase of the cell growth from 7.4 to $12.1 \mathrm{~g} \mathrm{~L}^{-1}$ was observed when pH value increased from 3.5 to 5.0 (Table 1). Biosynthesis of PA was dependent on the $\mathrm{pH}$ and ranged from 38.0 to $55.0 \mathrm{~g} \mathrm{~L}^{-1}$. The highest PA concentration and parameters of PA production were obtained in the culture with $\mathrm{pH}$ of 4.5. Under such conditions, the yield of PA formation reached $0.54 \mathrm{~g} \mathrm{~g}^{-1}$, whereas volumetric and specific productivity amounted to $0.75 \mathrm{~g} \mathrm{~L}^{-1} \mathrm{~h}^{-1}$ and $0.07 \mathrm{~g} \mathrm{~g}^{-1} \mathrm{~h}^{-1}$, respectively. Moreover, in the culture with $\mathrm{pH} 4.5$, a comparatively low formation of KGA $\left(11.9 \mathrm{~g} \mathrm{~L}^{-1}\right)$ was observed, whereas, under other $\mathrm{pH}$ conditions, the yeast was able to produce up to $15.4 \mathrm{~g} \mathrm{~L}^{-1}$ of this acid. On the basis of data from this experiment, $\mathrm{pH} 4.5$ was indicated as the most suitable for PA production by examined strain of Y. lipolytica. According to Kamzolova and Morgunow (2016) during the biosynthesis of PA by Blastobotrys adeninivorans, $\mathrm{pH}$ of the culture broth was maintained at 4.5 which allowed to obtain $43.2 \mathrm{~g} \mathrm{~L}^{-1}$ of PA from $100 \mathrm{~g} \mathrm{~L}^{-1}$ of glucose. It is a significantly lower amount than was produced under the same $\mathrm{pH}$ conditions by $Y$. lipolytica from $100 \mathrm{~g} \mathrm{~L}^{-1}$ of glycerol in this study. In other literature reports concerning biosynthesis of PA by different microorganisms (Liu et al. 2004; Morgunov et al. 2004; Wang et al. 2012; Yang et al. 2014; Zhang and Gao 2007), the $\mathrm{pH}$ of the culture media was maintained at a similar level (4.5-5.5) as indicated in this work.

\section{The impact of thiamine on PA formation}

The natural feature of $Y$. lipolytica yeast is the lack of ability to synthesize the pyrimidine structure of the thiamine molecule. Therefore, for normal growth, the yeast requires their growth media to be supplemented with this vitamin at a concentration of about $200 \mu \mathrm{g} \mathrm{L}^{-1}$ (Chernyavskaya et al. 2000). In cell metabolism, thiamine acts as a cofactor of pyruvate dehydrogenase complex (PDH). A deficiency of this vitamin might cause a decrease of PDH activity and thus lead to the reduction of further transformation of PA ( $\mathrm{Li}$ et al. 2001). Therefore, intentional limitation of thiamine in the culture 
of the thiamine-auxotrophic yeast $Y$. lipolytica creates a possibility for enhancing PA accumulation and excretion to the culture broth. In the presented study, the influence of thiamine on PA synthesis by $Y$. lipolytica was examined in the media with vitamin concentration that varied from 0 to $3.5 \mu \mathrm{g} \mathrm{L}^{-1}$. As a result of increasing thiamine concentration, an increase in biomass level was observed in the studied cultures (Table 2). The highest biomass concentration observed when $3.5 \mu \mathrm{g} \mathrm{L}^{-1}$ of thiamine was applied reached $14.4 \mathrm{~g}$ $\mathrm{L}^{-1}$ and was considerably higher than in the culture without the vitamin addition where it amounted to $11.6 \mathrm{~g} \mathrm{~L}^{-1}$. In the culture without thiamine supplementation, the yeast was able to produce $55.0 \mathrm{~g} \mathrm{~L}^{-1}$ of PA and $11.9 \mathrm{~g} \mathrm{~L}^{-1}$ of KGA. Despite the fact that, in this culture, bioreactor medium did not contain thiamine, it should be noted that some amount of the vitamin was introduced to the bioreactor with inoculation culture (as a component of commercial YNB medium) and was the reason for comparably good growth of the yeast in the bioreactor culture. Addition of $1 \mu \mathrm{g} \mathrm{L}{ }^{-1}$ of thiamine to the culture medium allowed to obtain a slightly improved PA biosynthesis $\left(57.8 \mathrm{~g} \mathrm{~L}^{-1}\right)$ and a lowered production of KGA $\left(7.2 \mathrm{~g} \mathrm{~L}^{-1}\right)$. In such conditions, the highest values of PA volumetric productivity and production yield were observed and reached $0.83 \mathrm{~g} \mathrm{~L}^{-1} \mathrm{~h}^{-1}$ and $0.56 \mathrm{~g} \mathrm{~g}^{-1}$, respectively. Moreover, when $1 \mu \mathrm{g} \mathrm{L}{ }^{-1}$ of thiamine was applied in the culture, the highest ratio of PA in the sum of acids (PA:(PA + KGA)) was noted (0.89). Further increase of the vitamin supplementation resulted in the significant drop of PA formation as well as a decrease in its production parameters. Summarizing, the obtained results indicate that thiamine limitation, at the initial level of $1 \mu \mathrm{g} \mathrm{L}^{-1}$, is appropriate for PA biosynthesis with the use of the examined strain of $Y$. lipolytica. Thus, this concentration was chosen for further experiments. In comparison, the most efficient PA production by $Y$. lipolytica 374/4 was observed when 2 and $3 \mu \mathrm{g} \mathrm{L}^{-1}$ of thiamine were added to the glucose- and glycerol-containing media, respectively (Morgunov et al. 2004). Hence, it should be noted that optimal concentration of thiamine, necessary for effective production of PA by Y. lipolytica, may depend on the applied strain, substrate, and composition of the inoculation media. In other studies on the biotechnological production of PA, the enhanced product formation was stimulated by application of limiting doses of the factors indispensable for growth of different auxotrophic microorganisms: thiamine in case of auxotrophs of Acinetobacter genus (Izumi et al. 1982), Schizophyllum commune (Takao and Tanida 1982), and Debaryomyces coudertii (Moriguchi 1982), lipoic acid in case of Escherichia coli (Yokota et al. 1994), arginine (Miyata et al. 1989a), and isoleucine/valine (Miyata et al. 1989b) in case of mutant strains of Torulopsis glabrata, and a carefully balanced media with appropriate concentration of biotin, nicotinic acid, pyridoxine, and thiamine in case of a multi-vitamin auxotroph of $T$. glabrata (Yonehara and Miyata 1994).

\section{The effect of agitation on the production of PA}

The ability of PA production by Y. lipolytica Wratislavia 1.31 was investigated under different stirring conditions: 600,800 , and $1000 \mathrm{rev} \mathrm{min}^{-1}$. The best results were achieved

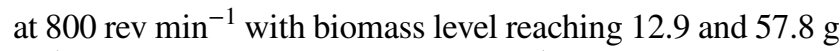
$\mathrm{L}^{-1}$ of PA being produced at $0.56 \mathrm{~g} \mathrm{~g}^{-1}$ yield and production rate of $0.83 \mathrm{~g} \mathrm{~L}^{-1} \mathrm{~h}^{-1}$ (Table 3). An additional variant where culture was started at the stirrer speed of $1000 \mathrm{rev} \mathrm{min}^{-1}$ and switched to $800 \mathrm{rev} \mathrm{min}^{-1}$ after $24 \mathrm{~h}$ of cultivation was also performed. Concentration of PA obtained in that culture (55.1 $\mathrm{g} \mathrm{L}^{-1}$ ) was slightly lower than in the case of the culture conducted at $800 \mathrm{rev} \mathrm{min}^{-1}$. However, in the culture stirred at $1000 / 800 \mathrm{rev} \mathrm{min}^{-1}$, the biosynthesis time and production of KGA were slightly reduced and resulted in very similar yield, production rate, and ratio of PA in the sum of acids as compared to the culture stirred at $800 \mathrm{rev} \mathrm{min}^{-1}$. In contrast, for Torulopsis glabrata grown on glucose media, the best results of PA biosynthesis were observed when twostage oxygen supply strategy was applied in which, during the first phase, the agitation of $700 \mathrm{rev} \mathrm{min}^{-1}$ was used to stimulate cell growth. Subsequently, after $16 \mathrm{~h}$, the stirrer

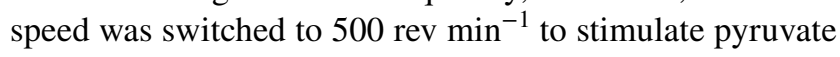
production ( $\mathrm{Li}$ et al. 2002). As a result, the process ended $69.4 \mathrm{~g} \mathrm{~L}^{-1}$ of PA was obtained from $112.0 \mathrm{~g} \mathrm{~L}^{-1}$ of glucose. In the experiment presented in this study at stirring speed of $800 \mathrm{rev} \mathrm{min}^{-1}$, the increased cell growth of Y. lipolytica corresponded to the increased production of PA.

\section{Substrate concentration affects PA production}

The $\mathrm{pH}$ of 4.5 , thiamine concentration of $1 \mu \mathrm{g} \mathrm{L}^{-1}$, and agitation rate of $800 \mathrm{rev} \mathrm{min}^{-1}$ were found to be the most favourable conditions for PA production when the medium with $100 \mathrm{~g} \mathrm{~L}^{-1}$ of glycerol was applied. In the next experiment, the effect of glycerol concentration on PA biosynthesis was examined by application of the medium with $150 \mathrm{~g}$ $\mathrm{L}^{-1}$. The comparison of the cultures results obtained in the same conditions with different glycerol concentration showed that in the process, with an increased substrate concentration $\left(150 \mathrm{~g} \mathrm{~L}^{-1}\right)$, growth of the examined strain reached $11.7 \mathrm{~g} \mathrm{~L}^{-1}$ (Fig. 1) and was slightly lower than in cultures with $100 \mathrm{~g} \mathrm{~L}^{-1}$ of glycerol added to the medium (Table 3) where it was $12.9 \mathrm{~g} \mathrm{~L}^{-1}$. In conditions of higher availability of the substrate, the yeast was able to produce more PA $\left(65 \mathrm{~g} \mathrm{~L}^{-1}\right)$ with simultaneous significant increase of KGA production $\left(20.2 \mathrm{~g} \mathrm{~L}^{-1}\right)$. Hence, unfavourable change of the ratio of PA in the sum of acids (0.76) was observed under increased glycerol concentration. Moreover, in comparison with the culture with lower glycerol 


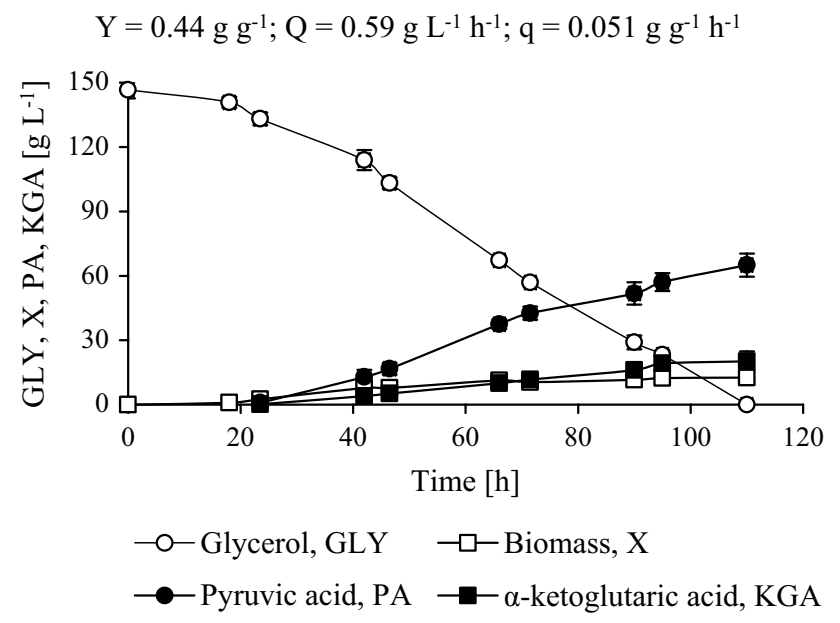

Fig. 1 Growth of Y. lipolytica and production of pyruvic acid on glycerol medium in batch culture. Culture conditions: $150 \mathrm{~g} \mathrm{~L}^{-1}$ of glycerol, thiamine concentration of $1 \mu \mathrm{g} \mathrm{L}^{-1}, \mathrm{pH} 4.5$, and agitation rate of 800 rev $\min ^{-1}$

concentration, application of $150 \mathrm{~g} \mathrm{~L}^{-1}$ of the substrate in the culture medium resulted in an extended duration of the process. Therefore, an observed drop of PA productivity and specific production rate to the following levels: $0.59 \mathrm{~g} \mathrm{~L}^{-1} \mathrm{~h}^{-1}$ and $0.051 \mathrm{~g} \mathrm{~g}^{-1} \mathrm{~h}^{-1}$, respectively. In
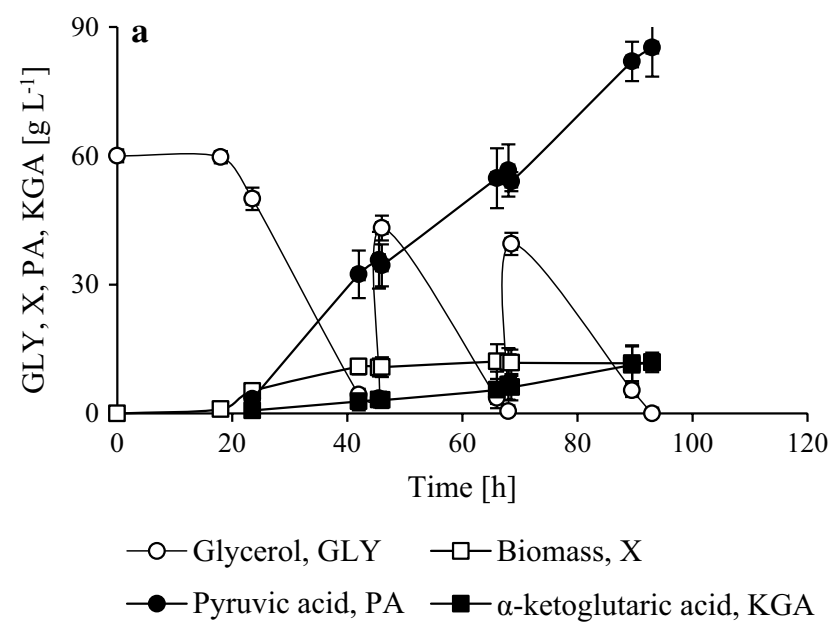

such conditions, the unfavourable decrease of PA yield $\left(0.44 \mathrm{~g} \mathrm{~g}^{-1}\right)$ was also noted.

\section{Production of PA under fed-batch cultivations}

To avoid the inhibitory effect of high substrate concentration on PA biosynthesis in the next step of the study, a fedbatch mode of cultivation was applied. The biosynthesis was initiated in the medium with comparatively low concentration of pure or crude glycerol $\left(60 \mathrm{~g} \mathrm{~L}^{-1}\right)$ and supplemented with two pulsed additions of the substrate during cultivation (Fig. 2a, b). As presented in Fig. 2a, the growth of yeast reached $11.5 \mathrm{~g} \mathrm{~L}^{-1}$ and was at the same level as in the batch culture with the same concentration of the substrate $(150 \mathrm{~g}$ $\mathrm{L}^{-1}$ ) in the culture medium. However, in contrast to the batch culture, fed-batch mode application allowed to obtain $85.2 \mathrm{~g}$ $\mathrm{L}^{-1}$ of PA within only $93 \mathrm{~h}$ which resulted in the highest value of volumetric production rate- $-0.92 \mathrm{~g} \mathrm{~L}^{-1} \mathrm{~h}^{-1}$. Moreover, under conditions of fed-batch culture, the yeast was able to synthesize significantly higher amount of PA without increasing production of KGA which resulted in the satisfactory ratio of PA in the sum of acids (0.88) and the upswing of PA production yield $\left(0.61 \mathrm{~g} \mathrm{~g}^{-1}\right)$ (Table 4$)$. The satisfactory results of application of high glycerol concentration in fed-batch mode lead to the idea of crude glycerol adaptation for the process (Fig. 2b). It was observed that application of
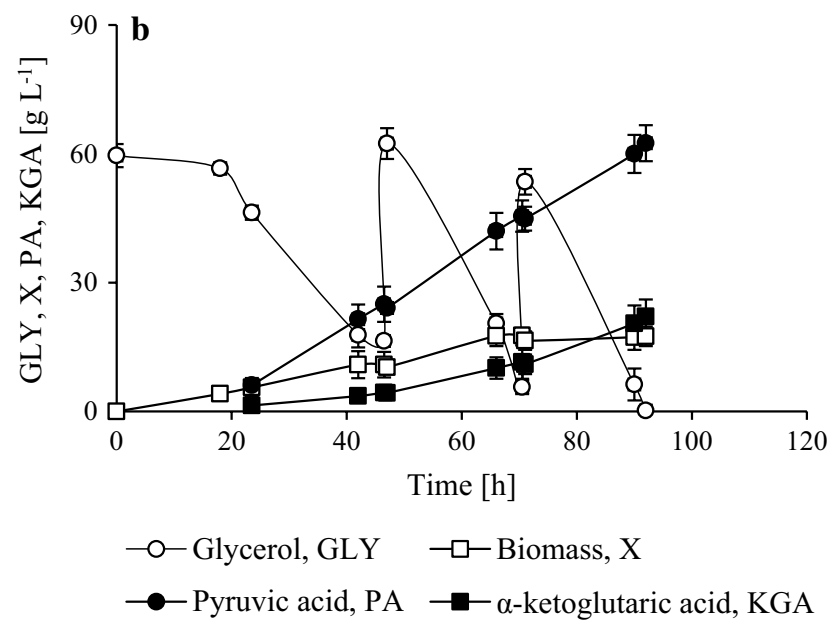

Fig. 2 Biosynthesis of pyruvic acid by Y. lipolytica on pure (a) and crude (b) glycerol media in fed-batch mode

Table 4 Pyruvic acid production parameters obtained on glycerol and crude glycerol media during fed-batch culture of Y. lipolytica Wratislavia 1.31

\begin{tabular}{|c|c|c|c|c|c|}
\hline Substrate & $Y\left(\mathrm{~g} \mathrm{~g}^{-1}\right)$ & $Q\left(\mathrm{~g} \mathrm{~L}^{-1} \mathrm{~h}^{-1}\right)$ & $q\left(\mathrm{~g} \mathrm{~g}^{-1} \mathrm{~h}^{-1}\right)$ & PA/total acids & $\eta_{\mathrm{PA}}$ \\
\hline Pure glycerol & 0.61 & 0.90 & 0.080 & 0.88 & 0.46 \\
\hline Crude glycerol & 0.41 & 0.70 & 0.046 & 0.74 & 0.31 \\
\hline
\end{tabular}

Culture conditions: $150 \mathrm{~g} \mathrm{~L}^{-1}$ of glycerol, thiamine concentration of $1 \mu \mathrm{g} \mathrm{L}-1, \mathrm{pH} 4.5$, and agitation rate of $800 \mathrm{rev}^{-1}$ 
crude substrate resulted in a yeast growth increased to a level of $14.8 \mathrm{~g} \mathrm{~L}^{-1}$, which might be explained by the impurities of natural origin, e.g., vitamins, usually found in this kind of substrate. A total time of fed-batch processes with both kinds of glycerol was almost the same; however, the amount of PA $\left(62.5 \mathrm{~g} \mathrm{~L}^{-1}\right)$ and KGA $\left(22.1 \mathrm{~g} \mathrm{~L}^{-1}\right)$ biosynthesized from the crude glycerol media were very similar to the results achieved in the batch process with pure glycerol, which is comparatively lower than in the fed-batch process with pure glycerol. The productivity and yield of PA formation from crude glycerol reached $0.68 \mathrm{~g} \mathrm{~L}^{-1} \mathrm{~h}^{-1}$ and $0.41 \mathrm{~g} \mathrm{~g}^{-1}$, respectively. Moreover, after crude substrate application, the changes in the produced ratio of PA:KGA was observed. It should be noted that the modification of the ratio of PA:KGA production might change in the presence of different factors, biotin included, contained as the impurities in crude glycerol (Cybulski et al. 2018).

It was reported that, in fed-batch culture of $Y$. lipolytica $374 / 4$ with pure glycerol media after $78 \mathrm{~h}$ of cultivation, $61.3 \mathrm{~g} \mathrm{~L}^{-1}$ of PA was detected, which corresponded to a specific production rate of $0.076 \mathrm{~g} \mathrm{~g}^{-1} \mathrm{~h}^{-1}$ (Morgunov et al. 2004). Therefore, our results showed that $Y$. lipolytica Wratislavia 1.31 was able to produce PA with higher volumetric and specific production rates in comparison to the findings of Morgunov et al. (2004). In addition, in the report by these researchers, it was presented that the process of PA production from glycerol by $Y$. lipolytica 374/4 was characterized by the energy yield coefficient $\left(\eta_{\mathrm{PA}}\right)$ of 0.53 and was higher when compared to the results of 0.44 published for glucosegrown yeast $T$. glabrata ( $\mathrm{Li}$ et al. 2002; Morgunov et al. 2004). In our study, the maximum energy yield coefficient value was obtained in fed-batch culture with pure glycerol and reached 0.46 (Table 4), and hence, it was higher than the result cited above for glucose. In the study on the production of PA from glucose by B. adeninivorans in fed-batch mode, cultivation yeast produced $43.2 \mathrm{~g} \mathrm{~L}^{-1}$ of PA (Kamzolova and Morgunov 2016). The yield of the PA biosynthesis calculated in the stationary phase of the culture, when the cell growth was ceased, was $0.77 \mathrm{~g} \mathrm{~g}^{-1}$. It is worth noting that in the presented study of PA production from glycerol by $Y$. lipolytica Wratislavia 1.31, the yield calculated for the stationary growth phase was significantly higher, because it reached $1.03 \mathrm{~g} \mathrm{~g}^{-1}$. Currently, T. glabrata is a strain of microorganisms used for commercial production of PA as its application allows to obtain high amounts of the acid (Xu et al. 2008). In the literature, the highest parameters of PA biosynthesis by these yeast were reported for mutant strain T. glabrata RS23 which produced $94.3 \mathrm{~g} \mathrm{~g}^{-1}$ of PA from $150.0 \mathrm{~g} \mathrm{~L}^{-1}$ of glucose, corresponding to the yield of $0.64 \mathrm{~g} \mathrm{~g}^{-1}$ (Liu et al. 2006). However, in biosynthesis of PA by T. glabrata, achieving high productivity is not possible without providing optimal nutrient environment, i.e., optimal and balanced concentration of nitrogen, thiamine, biotin, riboflavin, nicotinic acid, and pyridoxine (Yang et al. 2014). In view of these findings, the outcome of our experiments on PA production from glycerol by $Y$. lipolytica, auxotrophic only to thiamine, resulting in only a little lower PA concentration and the yield comparative to values reported for T. glabrata, seems to be very promising.

\section{Conclusions}

The cost of biotechnological production of 1 ton of PA from glucose is calculated at the level of $\$ 1255$, whereas chemical synthesis generates a cost as high as $\$ 8650(\mathrm{Li}$ et al. 2001). In this work, we offer the environmentally friendly biotechnological method of PA production that uses glycerol-considerably less expensive substrate than glucose, especially when crude glycerol is considered. In addition, of great importance seems to be the fact that application of glycerol does not meet with any sociological controversy, as it is in case of glucose (Dobson et al. 2012). Moreover, it should be noted that satisfactory production parameters of PA by other microorganisms were generally achieved only after application of genetically modified strains (Liu and Cao 2018; Luo et al. 2018; Zhang et al. 2017; Maleki and Eiteman 2017). In this work, we have presented a potential of not genetically modified $Y$. lipolytica yeast strain to produce PA from a renewable carbon source.

In the presented study, it was shown that PA biosynthesis by $Y$. lipolytica Wratislavia 1.31 was characterized by a comparable or higher value of PA production parameters than reported by other researchers for other microorganisms. Under optimal conditions, the examined yeast strain was able to produce $85 \mathrm{~g} \mathrm{~L}^{-1}$ of PA with the energy yield coefficient of 0.46 . The satisfactory results of the herein described experiments indicate that production of PA on simple glycerol-containing medium by $Y$. lipolytica was very promising and might be considered as an attractive alternative for currently used chemical methods of PA synthesis.

Acknowledgements Publication supported by Wrocław Centre of Biotechnology, programme The Leading National Research Centre (KNOW) for years 2014-2018.

Open Access This article is distributed under the terms of the Creative Commons Attribution 4.0 International License (http://creativeco mmons.org/licenses/by/4.0/), which permits unrestricted use, distribution, and reproduction in any medium, provided you give appropriate credit to the original author(s) and the source, provide a link to the Creative Commons license, and indicate if changes were made. 


\section{References}

Chernyavskaya OG, Shishkanova NV, Il'chenko AP, Finogenova TV (2000) Synthesis of alpha-ketoglutaric acid by Yarrowia lipolytica yeast grown on ethanol. Appl Microbiol Biotechnol 53:152-158. https://doi.org/10.1007/s002530050002

Cybulski K, Tomaszewska-Hetman L, Rakicka M, Łaba W, Rymowicz W, Rywińska A (2018) The bioconversion of waste products from rapeseed processing into keto acids by Yarrowia lipolytica. Ind Crop Prod 119:102-110. https://doi.org/10.1016/j.inder op.2018.04.014

Dobson R, Gray V, Rumbold K (2012) Microbial utilization of crude glycerol for the production of value-added products. J Ind Microbiol Biot 39:217-226. https://doi.org/10.1007/s10295-011-1038-0

Eisenberg A, Seip JE, Gavagan JE, Payne MS, Anton DL, DiCosimo R (1997) Pyruvic acid production using methylotrophic yeast transformants as catalyst. J Mol Catal B-Enzym 2:223-232. https://doi. org/10.1016/S1381-1177(96)00021-5

Hao JR, Ma CQ, Gao C, Qiu JH, Wang M, Zhang YN, Cui X, Xu P (2007) Pseudomonas stutzeri as a novel biocatalyst for pyruvate production from DL-lactate. Biotechnol Lett 29:105-110. https:// doi.org/10.1007/s10529-006-9204-6

Izumi Y, Matsumura Y, Tani Y, Yamada H (1982) Pyruvic acid production from 1,2-propanediol by thiamine-requiring Acinetobacter sp. 80-M. Agr Biol Chem 46:2673-2679. https://doi. org/10.1080/00021369.1982.10865515

Kamzolova SV, Morgunow IG (2016) Biosynthesis of pyruvic acid from glucose by Blastobotrys adeninivorans. Appl Microbiol Biotechnol 100:7689-7697. https://doi.org/10.1007/s0025 3-016-7618-1

Li Y, Chen J, Lun SY (2001) Biotechnological production of pyruvic acid. Appl Microbiol Biotechnol 57:451-459. https://doi. org/10.1007/s002530100804

Li Y, Hugenholtz J, Chem J, Lun SY (2002) Enhancement of pyruvate production by Torulopsis glabrata using a two-stage oxygen supply control strategy. Appl Microbiol Biotechnol 60:101-106. https ://doi.org/10.1007/s00253-002-1064-y

Liu M, Cao Z (2018) Regulation of NADH oxidase expression via a thermo-regulated genetic switch for pyruvate production in Escherichia coli. Biotechnol Bioproc Eng 23:93-99. https://doi. org/10.1007/s12257-017-0290-1

Liu LM, Li Y, Li HZ, Chen J (2004) Manipulating the pyruvate dehydrogenase bypass of a multi-vitamin auxotrophic yeast Torulopsis glabrata enhanced pyruvate production. Lett Appl Microbiol 39:199-206. https://doi.org/10.1111/j.1472-765X.2004.01563.x

Liu L, Xu Q, Li Y, Shi Z, Zhu Y, Du G, Chen J (2006) Enhancement of pyruvate production by osmotic-tolerant mutant of Torulopsis glabrata. Biotechnol Bioeng 97(4):825-832. https://doi. org/10.1002/bit.21290

Luo Z, Liu S, Du G, Xu S, Zhou J, Chen J (2018) Enhanced pyruvate production in Candida glabrata by carrier engineering. Biotechnol Bioeng 115:473-482. https://doi.org/10.1002/bit.26477

Ma CQ, Gao C, Qiu JH, Wang M, Zhang YN, Cui X, Xu P (2004) An enzymatic route to produce pyruvate from lactate. Appl Microbiol Biotechnol 66:34-39. https://doi.org/10.1007/s00253-004-1646-y

Maleki N, Eiteman MA (2017) Recent progress in the microbial production of pyruvic acid. Fermentation 3(1):8. https://doi. org/10.3390/fermentation3010008

Miyata R, Yonehara T, Yomoto K (1989a) Manufacture of pyruvic acid with Torulopsis species. JP patent 63258587

Miyata R, Tsutsui H, Yonehara T (1989b) Manufacture of pyruvic acid with Torulopsis species. JP patent 0155185
Morgunov IG, Kamzolova SV, Perevoznikova OA, Shishkanova NV, Finogenova TV (2004) Pyruvic acid production by a thiamine auxotroph of Yarrowia lipolytica. Process Biochem 39:14691474. https://doi.org/10.1016/S0032-9592(03)00259-0

Moriguchi M (1982) Fermentative production of pyruvic acid from citrus peel extract by Debaryomyces coudertii. Agr Biol Chem 46(4):955-961. https://doi.org/10.1080/00021369.1982.10865191

Moriguchi M, Shuto K, Hashimoto T (1984) Production of pyruvic acid from saccharified citrus peel extract by dried cells of Debaryomyces coudertii. J Ferment Technol 62:243-248

Ogawa J, Soong CL, Ito M, Shimizu S (2001) Enzymatic production of pyruvate from fumarate - an application of microbial cyclicimide-transforming pathway. J Mol Catal B-Enzym 11:355-359. https://doi.org/10.1016/S1381-1177(00)00024-2

Rywińska A, Bąk M, Rakicka M, Tomaszewska L, Boriczkowski T, Lazar Z, Musiał I, Rymowicz W (2012) Selection of the UV mutants of Yarrowia lipolytica yeast for erythritol biosynthesis form glycerol. Acta Sci Pol Biotechnologia 11:23-38

Song Y, Li J, Shin H, Liu L, Du G, Chen J (2016) Biotechnological production of alpha-keto acids: current status and perspectives. Bioresour Technol 219:716-724. https://doi.org/10.1016/j.biort ech.2016.08.015

Takao S, Tanida M (1982) Pyruvic acid production by Schizophyllum commune: pyruvic acid fermentation by Basidiomycetes (I). J Ferment Technol 60:277-280

Wang Z, Gao C, Wang Q, Liang Q, Qi Q (2012) Production of pyruvate in Saccharomyces cerevisiae through adaptive evolution and rational cofactor metabolic engineering. Biochem Eng J 67:126131. https://doi.org/10.1016/j.bej.2012.06.006

Wang Z, Xiao W, Zhang A, Ying H, Chen K, Ouyang P (2016) Potential industrial application of Actinobacillus succinogenes NJ113 for pyruvic acid production by microaerobic fermentation. Korean J Chem Eng 33:2908-2914. https://doi.org/10.1007/s1181 4-016-0168-5

Xu P, Qiu J, Gao C, Ma C (2008) Biotechnological routes to pyruvate production. J Biosci Bioeng 105(3):169-175. https://doi. org/10.1263/jbb.105.169

Yang S, Chen X, Xu N, Liu L, Chen J (2014) Urea enhances cell growth and pyruvate production in Torulopsis glabrata. Biotechnol Prog 30(1):19-27. https://doi.org/10.1002/btpr.1817

Yokota A, Shimizu H, Terasawa Y, Takaoka N, Tomita F (1994) Pyruvic acid production by a lipoic acid auxotroph of Escherichia coli W1485. Appl Microbiol Biotechnol 41(6):638-646. https://doi. org/10.1007/BF00167278

Yonehara T, Miyata R (1994) Fermentative production of pyruvate from glucose by Torulopsis glabrata. J Ferment Bioeng 78(2):155-159. https://doi.org/10.1016/0922-338X(94)90255-0

Zelić B, Gostović S, Vuorilehto K, Vasić-Racki D, Takors R (2004) Process strategies to enhance pyruvate production with recombinant Escherichia coli: from repetitive fed-batch to in situ product recovery with fully integrated electrodialysis. Biotechnol Bioeng 85(6):638-646. https://doi.org/10.1002/bit.10820

Zhang J, Gao N (2007) Application of response surface methodology in medium optimization for pyruvic acid production of Torulopsis glabrata TP19 in batch fermentation. J Zhejiang Univ Sci B 8(2):98-104. https://doi.org/10.1631/jzus.2007.B0098

Zhang B, Zhu Y, Zhang J, Wang D, Sun L, Hong J (2017) Engineered Kluyveromyces marxianus for pyruvate production at elevated temperature with simultaneous consumption of xylose and glucose. Bioresour Technol 224:553-562. https://doi.org/10.1016/j. biortech.2016.11.110 